\title{
A prospective observational to study sociodemographic profile, clinical profile and pattern of gynecological malignancies in a tertiary care center in Himachal Pradesh
}

\author{
Ashritha Ravindran*, Rajeev Sood, Kalpna Negi
}

Department of Obstetrics and Gynecology, Indira Gandhi Medical College, Shimla, Himachal Pradesh, India

Received: 05 September 2021

Revised: 11 October 2021

Accepted: 12 October 2021

\section{*Correspondence:}

Dr. Ashritha Ravindran,

E-mail: ashritharavindran@gmail.com

Copyright: () the author(s), publisher and licensee Medip Academy. This is an open-access article distributed under the terms of the Creative Commons Attribution Non-Commercial License, which permits unrestricted non-commercial use, distribution, and reproduction in any medium, provided the original work is properly cited.

\begin{abstract}
Background: Cancer is the second leading cause of death globally and is estimated to account for 9.6 million deaths in 2018. Due to the lack of cancer awareness, variable pathology, and dearth of proper screening facilities in developing countries such as India, most women report at advanced stages, adversely affecting the prognosis and clinical outcomes. The aim of the study was to study the sociodemographic profile, clinical profile, pattern of gynaecology malignancies and their histopathological findings of all gynaecological malignancy patients attending gynaecological OPD.

Methods: A prospective observational study was conducted in the Department of OBG, KNH Shimla from June 2019 to May 2020 where 241 gynaecological malignancy patients were recruited. Detailed history, general physical examination, systemic, gynaecological examination and required investigation was done and the data was analysed.

Results: The most commonly occurring gynaecological malignancy was cervical cancer. $82.2 \%$ of the patients belonged to the age group 40-69 years. Majority of the patients were multiparous, belonged to rural background, belonged to Hindu community. $69.3 \%$ were menopausal. Among the 132 women who gave history of age at first coitus as less than 18 years, $60.6 \%$ of them had cervical cancer. Most common presenting complaints was post-menopausal bleeding. In cervical cancer $43.6 \%$ of patients diagnosed at stage III and were managed by radiation therapy.

Conclusions: According to this study, cervical cancer is the most common gynaecological malignancy followed by ovarian cancer. Most of these patients seeked medical attention in advanced stage.
\end{abstract}

Keywords: Cervical cancer, Gynecological malignancy, Post-menopausal bleeding

\section{INTRODUCTION}

Malignant tumors are collectively referred to as cancers, derived from the Latin word for "crab"- that is, they adhere to any part that they seize in an obstinate manner, similar to a crab's behavior. ${ }^{1}$

It is estimated that about 9.6 million deaths occurred in 2018 due to cancer, hence being the second leading cause of death globally. About 1 in 6 deaths are attributable to cancer as its cause. ${ }^{2}$
Among female reproductive tract cancer cervical, endometrial and ovarian cancers are more common than vulvar, vaginal, fallopian tube cancers and choriocarcinoma which are rare.

Majority of India's female population reside in rural areas, where her access to health facility is further compromised by sociocultural, economical and environmental factors.

Due to the lack of cancer awareness, variable pathology, and dearth of proper screening facilities in developing countries such as India, most women report at advanced 
stages, adversely affecting the prognosis and clinical outcomes. $^{3}$

The first step in controlling the cancer burden in each population is to know their status in the population and collect information about the incidence. Several cancer incidence data sources have been used to measure cancer burden across the world. ${ }^{4}$

Cancer are commonly diagnosed in the late stage in developing countries, which has an economic impact on the country and is associated with lower survival, greater morbidity state. Hence, prevention is the most costeffective strategy. Early diagnosis and appropriate treatment can drastically reduce the morbidity and mortality. ${ }^{4}$

In India, most present in advanced stages and palliative care and pain relief are essential to provide good quality life for these patients.

This prospective observational study was undertaken to study the demographic profile, clinical profile of patients with genital malignancies and to understand the patterns of gynecological malignancies in hill state, Himachal Pradesh of India.

\section{METHODS}

This prospective observational study was conducted in the Department of Obstetrics and Gynaecology, Kamla Nehru Hospital, Shimla for a period of year from June 2019 to May 2020.

All patients attending gynecology out patient department of Obstetrics and Gynecology $\mathrm{KNH}$ with genital malignancy was included in our study. A participant's information cum consent form was distributed to prospective participants and they were briefed about the study and its purpose. Written informed consent was obtained from each participant. Voluntary participation was encouraged.

\section{Inclusion criteria}

All patients attending the gynaecology OPD of Kamla Nehru Hospital, Shimla with genital malignancy.

\section{Exclusion criteria}

Follow up case of genital malignancy, post-operative patients, post chemoradiation patient.

Data was collected by using simple random sampling method.

Detailed history of the patient was taken. A thorough general physical examination, systemic examination, gynaecology examination and pelvic examination was done. After the completion of data collection, statistical analysis was done using SPSS 23.0 software. Results are summarized in tables, graphs and figures in terms of proportions and percentages.

\section{RESULTS}

A total of 241 patients were studied. Out of 241 cases, 140 cases $(58.1 \%)$ were of ca cervix, followed by 48 cases (20.7\%) of ca ovary, 38 cases $(15.8 \%)$ of corpus uteri ca, 11 cases $(4.6 \%)$ of ca vulva and 2 cases $(0.8 \%)$ of GTN (Table 1).

Table 1: Frequency of gynaecological malignancies.

\begin{tabular}{|lll|}
\hline Cervix & Frequency & Percentage \\
\hline Ovary & 140 & 58.1 \\
\hline $\begin{array}{l}\text { Uterine (endometrial } \\
\text { cancer + uterine sarcoma) }\end{array}$ & 50 & 20.7 \\
\hline Vulva & 38 & 15.8 \\
\hline GTN & 11 & 4.6 \\
\hline Total & 2 & 0.8 \\
\hline
\end{tabular}

The mean age in this study was 52.7 years. About $>81 \%$ belonged to age group 40-70 years (Table 2).

Table 2: Distribution among age frequency.

\begin{tabular}{|lll|}
\hline Age (years) & Frequency & Percentage \\
\hline $\mathbf{2 0 - 2 9}$ & 2 & 0.8 \\
\hline $\mathbf{3 0 - 3 9}$ & 15 & 6.2 \\
\hline $\mathbf{4 0 - 4 9}$ & 44 & 18.1 \\
\hline $\mathbf{5 0 - 5 9}$ & 64 & 26.3 \\
\hline $\mathbf{6 0 - 6 9}$ & 88 & 37 \\
\hline $\mathbf{2 7 0}$ & 26 & 11.5 \\
\hline Total & 241 & 100 \\
\hline
\end{tabular}

Majority of the patients (75.3\%) were educated below high school and $57.3 \%$ belonged to rural part of Himachal Pradesh. Also most of them $(94.7 \%)$ belonged to Hindu religion.

Table 3: Distribution according to smoking.

\begin{tabular}{|lll|}
\hline Smoking & Number & Percentage \\
\hline No & 198 & 82.2 \\
\hline Yes & 43 & 17.8 \\
\hline Total & 241 & 100 \\
\hline
\end{tabular}

$90 \%$ of them belonged to multiparous $69.3 \%$ were menopausal. 198 patients $(82.2 \%)$ was non-smokers (Table 3) and none of them consumed alcohol.

Symptoms at presentation are given in Table 4.

121 patients $(50.6 \%)$ came with primary complaint of post-menopausal bleeding, next common complaint was 
(14.1\%) with complaints of abdominal distension and menstrual irregularities.

Table 4: Distribution according to presenting complaints.

\begin{tabular}{|lll|}
\hline Complaint & Number & Percentage \\
\hline Postmenopausal bleeding & 121 & 50.6 \\
\hline Abdominal distension & 35 & 14.1 \\
\hline Pain abdomen & 13 & 5.0 \\
\hline Menstrual abnormalities & 32 & 13.3 \\
\hline Vaginal discharge & 21 & 8.3 \\
\hline Vulval growth & 11 & 4.6 \\
\hline Contact bleeding & 3 & 1.2 \\
\hline Incidental finding & 5 & 2.1 \\
\hline Total & 241 & 100 \\
\hline
\end{tabular}

Among cervical cancer and vulval cancer, most common variety seen was squamous cell carcinoma $(81.4 \%)$, in uterine cancer, most common variety seen was endometrioid type $(81.5 \%)$, in ovarian cancer was serous cystadenocarcinoma $(48 \%)$.

Table 5: Distribution according to primary treatment received.

\begin{tabular}{|lll|}
\hline \multicolumn{1}{|c|}{ Frequency } & Percentage \\
\hline Surgery & 109 & 44.8 \\
\hline Radiotherapy & 132 & 55.2 \\
\hline Total & 241 & 100 \\
\hline
\end{tabular}

$34.85 \%$ of them presented at stage 3 and as 132 out of 241 $(55.2 \%)$ presented at a later stage and were referred to department of radiotherapy for chemoradiation (Table 5).

\section{DISCUSSION}

One of the most important cause for morbidity and mortality in women is gynaecological cancer. Among them cervical cancer is the most common, even though there is an effective method to screen and treat the cancer. In our study $58 \%$ of them had cervical cancer which was similar in Jhansivani et al, Ethirajan et al and Chaudhary et al. ${ }^{6-8}$

The differences in the patterns of frequency of gynecological malignancy could be due to the differences in availability of screening, education, awareness, ethnicity, lifestyle, diet among the women. By adequate awareness and screening of all women in reproductive age group, premalignant lesion can be detected and its treatment can prevent disease progression, morbidity and mortality.

In our study mean age of cervical cancer, uterine cancer, ovarian cancer, GTN, vulval cancer are 52.6, 56.8, 48.9, 61.8 and 25 years respectively and in the study conducted by Ethirajan et al the mean ages of cancer cervix, ovarian and corpus uteri were 51.1, 53.3 and 47.2 years respectively. ${ }^{8}$

In this study most the patient belonged to rural part of the state, with education less than high school and belonged to Hindu community. It was similar to the finding in the study conducted by Chaudhary et al and Neha et al. Lack of education can be linked with early marriage, early childbirth, high parity which are risk factors for cancers like cancer cervix. Hence improving the education of the women is also essential to reduce the incidence of gynaecological cancer in developing countries like India. $^{7,11}$

In our study, $90 \%$ of the patients who presented with gynaecological malignancy were multiparous. This was similar in studies conducted by Chaudhary et al, Afroz et al. ${ }^{7,12}$

Most of patients were menopausal was comparable to other studies conducted by Ethirajan et al. ${ }^{8}$

Most common histopathology of cervical cancer were squamous cell carcinoma. Similar observations were made by Chaudhary et al, Afroz et al, Karim et al and Yakasai et al. Among ovarian cancer epithelial cell carcinoma is the most common which is similar to the finding in Chaudhary et al, Afroz et al, Manzoor et al, Yakasai et al. $100 \%$ of the cases of vulval cancer showed squamous cell carcinoma which was similar to the studies conducted by Chaudhary et al, Afroz et al, Agarwal et al and Karim et al. 5,7,9,10,12,13

In this study $44.8 \%$ underwent surgical management followed by chemoradiation and $55.2 \%$ were referred to department of radiotherapy for management.

This study has some limitations. Only patients who attended the OPD were included, whereas patients who were directly referred to the department of radiotherapy was not. Therefore this study did not include all patients of gynecological malignancy in the state of Himachal Pradesh.

\section{CONCLUSION}

According to this study, cervical cancer is the most common gynaecological malignancy followed by ovarian cancer and corpus uteri cancer. Most of these patients sought medical attention in advanced stage. Though cancer cervix is a preventable and easily accessible cancer, its incidence is high. This shows the importance of education, public awareness among the female population of developing countries like India. Also strengthening the health programs is an important step, to increase screening of premalignant lesion and this should be done in younger population as well. Proper screening, an early diagnosis and treatment may help to preserve the fertility and to decrease mortality. Along with this provision of accessible and affordable health care to lower socioeconomic group 
is essential. This would help in reducing morbidity and mortality due to gynaecological cancer.

Funding: No funding sources

Conflict of interest: None declared

Ethical approval: The study was approved by the Institutional Ethics Committee

\section{REFERENCES}

1. Kumar V, Abbas AK, Aster JC, eds. Robbins Basic Pathology. 10th edn. Canada: Elsevier; 2018.

2. World health organization. Cancer. Available from: https://www.who.int/news-room/factsheets/detail/cancer. Accessed on 11 May 2020.

3. Maheshwari A, Kumar N, Mahantshetty U. Gynecological cancers: a summary of published Indian data. South Asian J Cancer. 2016;5:112-20.

4. Devi KU. Current status of the gynaecological cancer care in India. J Gynecol Oncol. 2009;2:77-80.

5. Yakasai IA, Ugwa EA, Otubu J. Gynecological malignancies in Aminu Kano Teaching Hospital Kano: a 3-year review. Nigerian J Clin Pract. 2013;16(1):63-6.

6. Dr.Jhansivani YMD, Rani S. Epidemiology of gynecological cancers in a teritiary care center (Government General Hospital, Guntur). IOSR J Dent Med Sci. 2015;14(9, II):41-5.

7. Chaudhary S, Singhal SR, Gupta A. Study of sociodemographic profile and pattern of gynaecological malignancies in a tertiary care center. Int J Reprod Contracept Obstet Gynecol. 2016;5(8):2640-4.
8. Ethirajan S, Mohanapriya D, Aarthi C. Study on pattern of gynaecological malignancies at Saveetha Medical College and Hospital, Tamil Nadu, India. Int J Reprod Contracept Obstet Gynecol. 2018;7:3343-7.

9. Karim R, Wahab S, Begum S, Jamala F, Kishwar N, Hassan A. Frequency and pattern of gynaecological malignancies at a tertiary care hospital, Peshawar. An overview of five years of a retrospective study. JKCD. June 2019:9(2):45-8.

10. Agarwal S, Malhotra KP, Sinha S, Rajaram S. Profile of gynecologic malignancies reported at a tertiary care center in India over the past decade: comparative evaluation with international data. Indian J Cancer 2012;49:298-302.

11. Dahiya N, Bachani D, Acharya AS, Sharma DN, Gupta S, Haresh KP. Socio-demographic, reproductive and clinical profile of women diagnosed with advanced cervical cancer in a tertiary care institute of Delhi. J Obstet Gynecol India. 2017;67(1):53-60.

12. Afroz S, Ara G, Sultana F. Pattern of gynaecological malignancies in a tertiary care hospital. Open J Obstet Gynecol. 2019;9(04):449.

13. Manzoor H, Naheed H, Ahmad K, Iftikhar S, Asif M, Shuja J, et al. Pattern of gynaecological malignancies in south western region of Pakistan: an overview of 12 years. Biomed Rep. 2017;7(5):487-91.

Cite this article as: Ravindran A, Sood R, Negi K. A prospective observational to study sociodemographic profile, clinical profile and pattern of gynecological malignancies in a tertiary care center in Himachal Pradesh. Int J Reprod Contracept Obstet Gynecol 2021;10:4263-6. 